\title{
Calculation of Magnetic Flux Density Harmonics in the Vicinity of Overhead Lines
}

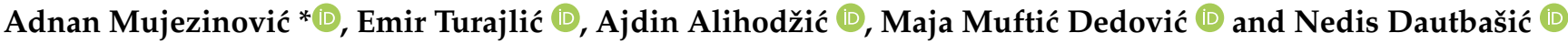 \\ Faculty of Electrical Engineering, University of Sarajevo, 71000 Sarajevo, Bosnia and Herzegovina; \\ eturajlic@etf.unsa.ba (E.T.); aalihodzic1@etf.unsa.ba (A.A.); maja.muftic-dedovic@etf.unsa.ba (M.M.D.); \\ nd15231@etf.unsa.ba (N.D.) \\ * Correspondence: adnan.mujezinovic@etf.unsa.ba
}

Citation: Mujezinović, A.; Turajlić, E.; Alihodžić, A.; Dedović, M.M. Dautbašić, N. Calculation of Magnetic Flux Density Harmonics in the Vicinity of Overhead Lines. Electronics 2022, 11, 512. https:// doi.org/10.3390/electronics11040512

Academic Editors: Giulio Antonini,

Daniele Romano and Luigi Lombardi

Received: 30 December 2021

Accepted: 5 February 2022

Published: 9 February 2022

Publisher's Note: MDPI stays neutral with regard to jurisdictional claims in published maps and institutional affiliations.

Copyright: (c) 2022 by the authors Licensee MDPI, Basel, Switzerland. This article is an open access article distributed under the terms and conditions of the Creative Commons Attribution (CC BY) license (https:// creativecommons.org/licenses/by/ $4.0 /)$

\begin{abstract}
This paper considers the method for the calculation of magnetic flux density in the vicinity of overhead distribution lines which takes into account the higher current harmonics. This method is based on the Biot-Savart law and the complex image method. The considered method calculates the values of the magnetic flux density for each harmonic component of the current separately at all points of interest (usually lateral profile). In this way, it is possible to determine the contributions of individual harmonic components of the current intensity to the total value of magnetic flux density. Based on the contributions of individual harmonic components, the total (resultant) value of the magnetic flux density at points of interest is determined. Validation of the computational method is carried out by comparison of the results obtained by the considered calculation method with measurement results. Furthermore, the application of the calculation method was demonstrated by calculating magnetic flux density harmonics in the vicinity of two overhead distribution lines of typical phase conductor arrangements.
\end{abstract}

Keywords: Biot-Savart (BS) law based method; current intensity harmonics; magnetic flux density harmonics; overhead lines

\section{Introduction}

Advances in technology and increased energy requirements have brought with them a significant increase in the number of nonlinear loads, as well as the use of converter-based distributed generation units. Nowadays, a large number of such units are connected to the networks. As previously stated, this brings into the networks the problem of harmonic pollution $[1,2]$.

The presence of a large number of nonlinear devices in the network causes harmonic pollution to become one of the most common power quality problems. Harmonic currents cause numerous detrimental side effects (heating, accelerated aging and capacity reduction), primarily on lines and transformers, but also on other equipment in the distribution network. They can also cause unwanted activation of protection devices, malfunctions of sensitive devices, interference in communication systems, and the reduction of useful torque of induction motors [3-5].

Due to the negative effects that harmonics have on the electrical equipment, which results in financial losses, it is important to limit harmonic currents injection [6]. For this purpose, international and national organizations defined the limits for each harmonic amplitudes, in relation to the fundamental one, as well as the limits of the total harmonic distortion (THD) [7-9]. "IEEE Recommended Practice and Requirements for Harmonic Control in Electric Power Systems" limits the harmonic distortion at the point of common coupling, and defines the limit values for up to the 50th harmonic. This standard prescribes different harmonic limits depending on the system rated voltage [7]. International Electrotechnical Commission published series of standards "IEC 61000-3:2022 SER-Electromagnetic compatibility" where different standards treat harmonic emissions in 
public low-voltage systems and the connection of distorting installations in medium, high and extra high voltage systems [9].

In order to meet these limitations, various methods are being developed to mitigate harmonic emission. Harmonic emission mitigation methods are classified into three categories: passive, active, and hybrid methods. Choosing the most appropriate method for mitigating harmonic emission is a demanding process, and it should be borne in mind that some of the methods are highly dependent on network conditions, while others can cause resonant phenomena $[10,11]$.

Nonlinear loads have a tendency to change their input impedance over the time and this has a significant impact on their current harmonic emission. Thus, the network harmonic impedance can be used to characterize the impact of individual nonlinear devices on harmonic currents emission in the grid [12], which can be useful for proper harmonic limiting method selection.

Investigations of possible adverse health issues associated with exposure to magnetic fields is of great research interest in recent decades. Numerous studies are conducted in order to find the exact mechanism of the impact of these phenomena on humans, as well as to establish consequences of that exposure [13-17]. Based on the experimental research and the statistical analyses of the relationship between the magnetic field exposure and the occurrences of severe diseases, the International Commission on Non-Ionizing Radiation Protection (ICNIRP) [18] published guidelines for limiting exposure to time-varying electric and magnetic fields in the frequency range $(1 \mathrm{~Hz}-100 \mathrm{kHz})$. These guidelines relate to instances when the fields are caused by pure sine currents and voltages, but also instances when their harmonic distortion is present. The guidelines cover all magnetic flux density harmonics which may occur in power system facilities. Since harmonic standards cover limit values up to the 50th harmonic, which for a system with fundamental frequency of $50 \mathrm{~Hz}$ corresponds to a frequency $2500 \mathrm{~Hz}$, or $3000 \mathrm{~Hz}$ for the systems with a fundamental frequency of $60 \mathrm{~Hz}$, it is interesting to note exposure limit values for that frequency range. For occupational exposure to time varying magnetic fields ICNIRP limit values are $1 \times 10^{-3} \mathrm{~T}$ in a frequency range from $25 \mathrm{~Hz}$ to $300 \mathrm{~Hz}$, and $0.3 / f \mathrm{~T}$ for a frequency range from $300 \mathrm{~Hz}$ to $3 \mathrm{kHz}$, where $f$ is the frequency of the analysed field. For general public exposure, the limit values for various frequency ranges are defined in a slightly different way. For a frequency range from $50 \mathrm{~Hz}$ to $400 \mathrm{~Hz}$ the limit value is $2 \times 10^{-4} \mathrm{~T}$ and for a frequency range from $400 \mathrm{~Hz}$ to $3 \mathrm{kHz}$, the limit value is defined as $8 \times 10^{-2} / f \mathrm{~T}$. When it comes to simultaneous exposure to multiple frequency fields, which is the case in the vicinity of power facilities with currents polluted by harmonics, specific criterion regarding reference levels should be applied [18]. According to these criteria, the influence of fields of all frequencies is summed up and the exposure limit value can be violated even if the fields at all frequencies individually meet the limit values.

It is important to perform magnetic flux density determination in the vicinity of overhead lines, as one of the strongest field sources. It is often assumed that if the magnetic flux density of the fundamental harmonic satisfies the prescribed reference levels than the harmonic magnetic flux density also satisfies them. However, this does not have to be the case in situations where currents with a large presence of higher harmonics flow through overhead lines $[19,20]$.

In this paper, a method for magnetic flux density harmonics calculation in the vicinity of overhead lines is considered. The method is validated by comparing the results obtained by the considered method to the measurement results. Furthermore, the considered method is applied to calculate magnetic flux density harmonics in the case of a currently operational medium voltage overhead lines.

The remainder of this paper is organized as follows. Section 2 provides a detailed description of the considered calculation method for the calculation of magnetic flux density harmonics. In Section 3, a comparison of the results obtained by considered calculation method with the measurement results is given. Section 4 considers the application of the considered calculation method on a case of two overhead distribution lines of a typical configuration of phase conductors. Section 5 concludes the paper. 


\section{Calculation Method}

In order to analyse magnetic flux density harmonics it is necessary to consider the exact phase current conditions. In overhead lines with the presence of higher current harmonics, phase current waveforms have the general form:

$$
\begin{aligned}
& i_{a}(t)=\sqrt{2} \sum_{h=1}^{N} I_{a}^{(h)} \sin \left(h \omega t+\theta_{a}^{(h)}\right) \\
& i_{b}(t)=\sqrt{2} \sum_{h=1}^{N} I_{b}^{(h)} \sin \left(h \omega t+\theta_{b}^{(h)}\right) \\
& i_{c}(t)=\sqrt{2} \sum_{h=1}^{N} I_{c}^{(h)} \sin \left(h \omega t+\theta_{c}^{(h)}\right),
\end{aligned}
$$

where: $i_{a}(t), i_{b}(t), i_{c}(t)$ are phase current waveforms, $N$ is the total number of considered harmonics, $h$ denotes the harmonic under a consideration, $I_{a}^{(h)}, I_{b}^{(h)}, I_{c}^{(h)}$ are root mean square (RMS) values of phase current intensities of $h$-th harmonic, $\omega$ is fundamental harmonic angular frequency, and $\theta_{a}^{h}, \theta_{b}^{h}, \theta_{c}^{h}$ are $h$-th harmonic phase angles associated with the phase currents.

It is important to note that not all current harmonics behave in the same manner as the fundamental harmonic. According to symmetrical component theory, current harmonics can be categorized into three different sequences: direct, inverse, and zero. The phase angles for direct, inverse and zero sequence harmonics are defined by the Equations (4)-(6), respectively $[19,20]$ :

$$
\begin{gathered}
{\left[\begin{array}{l}
\theta_{a}^{(h)} \\
\theta_{b}^{(h)} \\
\theta_{c}^{(h)}
\end{array}\right]=\left[\begin{array}{c}
0 \\
e^{-j \frac{2 \pi}{3}} \\
e^{j \frac{2 \pi}{3}}
\end{array}\right](h=3 \cdot k+1, k=0,1,2, \ldots)} \\
{\left[\begin{array}{l}
\theta_{a}^{(h)} \\
\theta_{b}^{(h)} \\
\theta_{c}^{(h)}
\end{array}\right]=\left[\begin{array}{c}
0 \\
e^{\frac{2 \pi}{3}} \\
e^{-j \frac{2 \pi}{3}}
\end{array}\right](h=3 \cdot k+2, k=0,1,2, \ldots)} \\
{\left[\begin{array}{l}
\theta_{a}^{(h)} \\
\theta_{b}^{(h)} \\
\theta_{c}^{(h)}
\end{array}\right]=\left[\begin{array}{l}
0 \\
0 \\
0
\end{array}\right](h=3 \cdot k, k=1,2,3, \ldots) .}
\end{gathered}
$$

For each considered calculation point in the vicinity of the overhead line, magnetic flux density can be calculated by applying the BS law based method [21]. This method considers every phase conductor as one current point source. Based on the equations for the calculation of magnetic flux density for fundamental harmonics [22], derived from the BS law based method, magnetic flux density for harmonics of a higher order can be calculated. The magnetic flux density for the entire lateral profile is calculated separately for each current harmonic. For the $h$-th order harmonic, the magnetic flux density phasor spatial components at an arbitrary calculation point $P(x, y)$ in the vicinity of the overhead distribution line can be calculated using the following equations:

$$
\begin{gathered}
\underline{B}_{x}^{(h)}(x, y)=\frac{\mu_{0}}{2 \pi} \cdot \sum_{i=1}^{n}\left(-\frac{y-y_{i}}{r_{i}^{2}}+\frac{y+y_{i}+\underline{\alpha}^{(h)}}{r_{i}^{\prime 2}}\right) \cdot \underline{I}_{i}^{(h)} \\
\underline{B}_{y}^{(h)}(x, y)=\frac{\mu_{0}}{2 \pi} \cdot \sum_{i=1}^{n}\left(\frac{x-x_{i}}{r_{i}^{2}}-\frac{x-x_{i}}{r_{i}^{\prime 2}}\right) \cdot \underline{I}_{i}^{(h)},
\end{gathered}
$$


where $\underline{B}_{x}^{(h)}(x, y)$ and $\underline{B}_{y}^{(h)}(x, y)$ are $x$ and $y$ vector components of the $h$-th harmonic magnetic flux density phasor, $\mu_{0}$ is the permeability of the air, $n$ is the total number of phase conductors, $\underline{I}_{i}^{(h)}$ is the current intensity of $h$-th harmonic of $i$-th phase conductor, $(x, y)$ are coordinates of an arbitrary calculation point, $\left(x_{i}, y_{i}\right)$ are coordinates of the $i$-th phase conductor, $\underline{\alpha}^{(h)}$ is the complex depth, $r_{i}$ is the shortest distance between the $i$-th phase conductor and calculation point, $r_{i}^{\prime}$ is the shortest distance between complex image of $i$-th phase conductor and calculation point.

The effect of ground surface is taken into account by using the complex image method. The complex depth is frequency dependent, therefore it can be calculated using the following equation $[23,24]$ :

$$
\underline{\alpha}^{(h)}=\frac{2}{\sqrt{-j \cdot \omega^{(h)} \cdot \mu_{0} \cdot\left(\sigma_{\text {soil }}-j \cdot \omega^{(h)} \cdot \varepsilon_{\text {soil }}\right)}},
$$

where $\omega^{(h)}$ is the $h$-th harmonic angular frequency, $\sigma_{\text {soil }}$ is soil conductivity, $\varepsilon_{\text {soil }}$ is dielectric permittivity of the soil.

The total magnetic flux density spatial vector components at an arbitrary calculation point can be obtained by applying the principle of superposition to include the contributions of each considered harmonic, as in:

$$
\begin{aligned}
B_{x}^{\text {tot }}(x, y) & =\sqrt{\sum_{h=1}^{N}\left|\underline{B}_{x}^{(h)}(x, y)\right|^{2}} \\
B_{y}^{\text {tot }}(x, y) & =\sqrt{\sum_{h=1}^{N}\left|\underline{B}_{y}^{(h)}(x, y)\right|^{2}},
\end{aligned}
$$

where $B_{x}^{\text {tot }}(x, y)$ and $B_{y}^{\text {tot }}(x, y)$ are magnetic flux density vector spatial components RMS values.

The resultant value of the total magnetic flux density with the presence of higher harmonics taken into account at some arbitrary point is defined as [21]:

$$
B^{t o t}(x, y)=\sqrt{\left|B_{x}^{t o t}(x, y)\right|^{2}+\left|B_{y}^{t o t}(x, y)\right|^{2}},
$$

where $B^{\text {tot }}(x, y)$ is the resultant value of the magnetic flux density at an arbitrary point with coordinates $(x, y)$.

THD of the magnetic flux density can be calculated using the following equation [25]:

$$
\operatorname{THD}_{B}(x, y)=\frac{\sqrt{\sum_{h=2}^{N} B^{(h)}(x, y)^{2}}}{B^{(1)}(x, y)} .
$$

The RMS value of magnetic flux density for each considered harmonic, including the fundamental one, can be calculated from the following equation:

$$
B^{(h)}(x, y)=\sqrt{\left|\underline{B}_{x}^{(h)}(x, y)\right|^{2}+\left|\underline{B}_{y}^{(h)}(x, y)\right|^{2}},
$$

where $B^{(h)}(x, y)$ is the RMS value of the $h$-th magnetic flux density at an arbitrary point with coordinates $(x, y)$.

\section{Calculation Method Validation}

In order to validate the proposed calculation method, a comparison between calculated and measured values is presented in this section. Two cases have been analysed. The first considered case is a simple low voltage three-phase horizontal conductor arrangement with previously published results. The second considered case corresponds 
to a three-phase distribution overhead line of $35 \mathrm{kV}$ rated voltage with horizontal phase conductor arrangement.

\subsection{Low-Voltage Experimental Case}

The method for the calculation of magnetic flux density harmonics in the vicinity of overhead lines is validated by the comparison of calculated magnetic flux density with measurement results given in the literature [26]. The measurements correspond to the three-phase configuration where conductors are placed at the same height, as shown in Figure 1a. Magnetic flux density calculation and measurements are performed at ground level over the considered lateral profile in increments of $25 \mathrm{~cm}$. Two cases are examined, without the presence of higher current harmonics, and with the presence of third current harmonic. The phase current intensity RMS value during the measurements is $4.58 \mathrm{~A}$ at frequency $16.666 \mathrm{~Hz}$, and the third harmonic current intensity is $0.7633 \mathrm{~A}$ at frequency $50 \mathrm{~Hz}$ [26]. For both cases, the comparison of magnetic flux density measurement results and the obtained calculation results for the considered test case are given in Figure $1 \mathrm{~b}$.

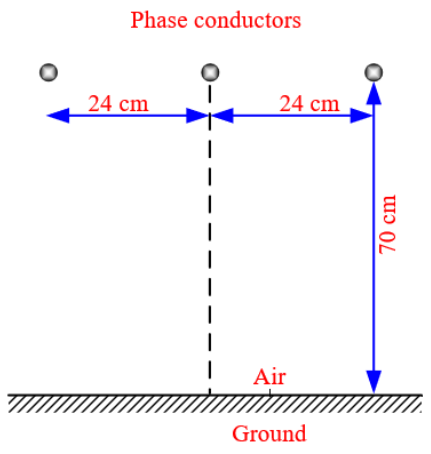

(a)

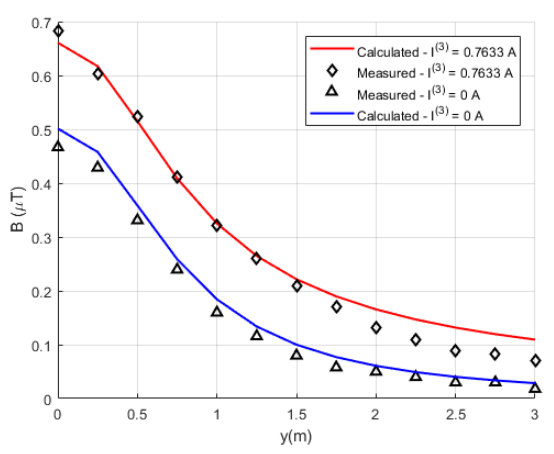

(b)

Figure 1. Considered validation case study. (a) Three-phase experimental configuration [26]. (b) Comparison of calculated and measured results.

From Figure $1 b$, it can be noted that there exists a high level of agreement between the measurement and the calculation magnetic flux density results in both considered cases; in the absence and in the presence of a third current harmonic in the system. Although magnetic flux density measurements were originally presented in Gauss [26], in this paper they are converted to SI system units. Measurements were extracted from the paper [26] using the WebPlotDigitizer tool [27], which may be the cause of certain deviations from the originally presented measurements.

In order to determine the level of agreement between the calculated and measured values, in both cases, mean square error (MSE) metric is used. In the case when there is no presence of higher harmonics, the mean square error is $4.08 \times 10^{-4}(\mu \mathrm{T})^{2}$, while in the case when there is a third harmonic in the considered system, the MSE value amounts to $6.62 \times 10^{-4}(\mu \mathrm{T})^{2}$.

There are certain deviations between the measurement and calculation results regardless of whether there is the presence of higher harmonics or not. It is interesting to note that, in the significant number of considered points observed deviations are larger in case without presence of third harmonic. Taking this into account it can be considered that the proposed model adequately takes into account the presence of higher harmonics. Deviations between measured and calculated values in both cases can be caused by low current intensity, which causes low magnetic flux density values, which are more difficult to register. Furthermore, although measurements are intended to be performed at floor level, it is difficult to set the sensor exactly at that level and due to the small height at which conductors are placed, this can significantly affect measured values. The small distances between the conductors and between the points where the magnetic flux density measurement are performed, can also have an impact on measured values. 


\subsection{Overhead Distribution Line Case}

The proposed calculation model is also validated in the case of the overhead distribution line of $35 \mathrm{kV}$ rated voltage. The phase conductor configuration of considered distribution line is shown in Figure 2a. The height of the phase conductors was determined by measurements using Suparule model 600 height meter, while the lateral distance between the phase conductors was taken from the technical specifications obtained from the local distribution company. The magnetic flux density has been measured by the 3D probe Narda-ELT 400 whose frequency range is from $1 \mathrm{~Hz}$ up to $400 \mathrm{kHz}$. Measurements are performed at the height of $1 \mathrm{~m}$ above ground surface. Measurements were performed from the distribution line axis to a distance of $20 \mathrm{~m}$ in one direction with increments of $1 \mathrm{~m}$. Simultaneously with the measurement of the magnetic flux density, the current intensity was also measured. The measurement of the current intensity and current harmonic spectrum was conducted by power quality analyser EPPE W8. These measurements were carried out in the distribution transformer station $(35 / 10 \mathrm{kV})$ which is supplied by the considered overhead distribution line. The power quality analyser was connected to the secondary windings of current measuring transformers that are placed on the lower voltage terminals (10 kV terminals) of the distribution transformer. The transmission ratio of the current measuring transformer is $600 / 5$ (A). Therefore, the measured values of current intensity were corrected by the transmission ratios of the current measuring transformer and the distribution transformer. The value of the fundamental harmonic intensity was $218.64 \mathrm{~A}$ at frequency $50 \mathrm{~Hz}$. The registered current harmonic content is given in Figure $2 \mathrm{~b}$.

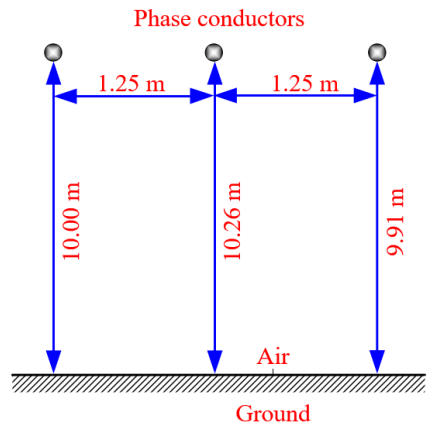

(a)

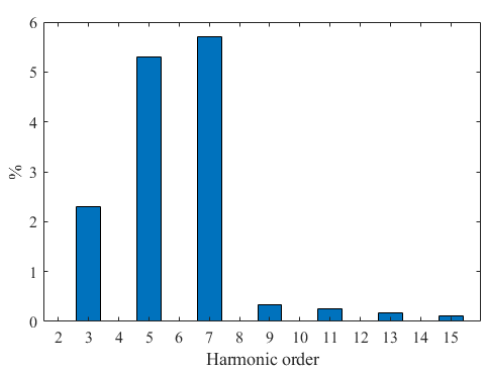

(b)

Figure 2. Considered $35 \mathrm{kV}$ horizontal overhead distribution line case. (a) $35 \mathrm{kV}$ overhead distribution line configuration. (b) Current harmonic spectrum.

A comparison between the measured and calculated magnetic flux density values is presented in Figure 3. It can be noted that the results of measurements and the calculations of magnetic flux density closely match. For this case, the calculated value of the mean square error equals $2.24 \times 10^{-3}(\mu \mathrm{T})^{2}$.

The observed deviations between the measurements and calculation results can be caused by numerous factors such as current intensity and current harmonic content variation during the measurement of the magnetic flux density, measurement transformer error and uneven terrain on location where magnetic flux density was measured.

The results of two analysed cases demonstrate that the considered calculation method can be used for magnetic flux density analysis in the vicinity of overhead lines with the presence of higher current harmonics. 


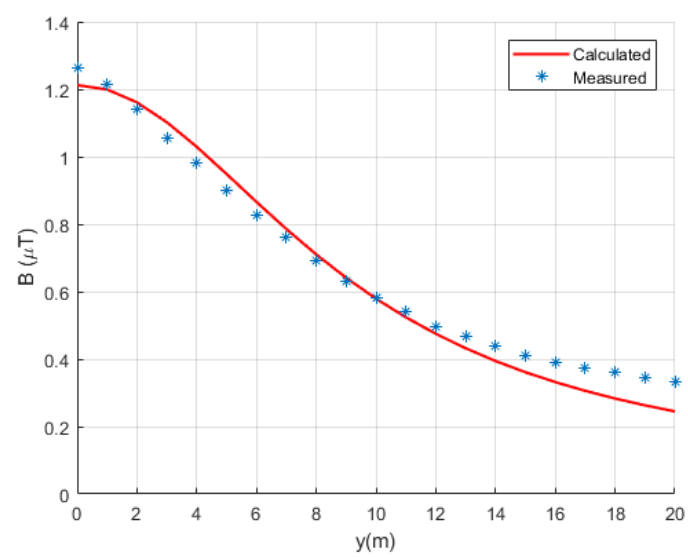

Figure 3. Comparison of calculated and measured values for analysed $35 \mathrm{kV}$ overhead distribution line.

\section{Case Studies}

The considered calculation method has been applied to perform a magnetic flux density harmonics calculation in the vicinity of two typical overhead distribution lines. The first case corresponds to a $10 \mathrm{kV}$ overhead distribution line of horizontal phase conductor configuration and the second case corresponds to a $35 \mathrm{kV}$ overhead distribution line. These overhead distribution line configurations are selected based on their widespread use, large human population proximity, and the presence of higher current harmonics in the medium voltage networks, due to a high number of nonlinear loads and distributed generation.

\subsection{Overhead Distribution Line of Horizontal Configuration}

The first considered overhead distribution line configuration is shown in Figure 4a. Calculations are performed for the rated current of phase conductors and the usual presence of higher current harmonics. For the $10 \mathrm{kV}$ rated voltage overhead line, the aluminium steel conductor with ampacity of $170 \mathrm{~A}$ is typically used. Calculations are performed for the converter-based distributed generator typical harmonic spectrum as in Table 1 [28,29].

Table 1. Considered current harmonic spectrum.

\begin{tabular}{ccc}
\hline Harmonic Order & Magnitude (\%) & Phase Angle (Rad) \\
\hline 1 & 100 & 0 \\
\hline 5 & 20 & 0 \\
\hline 7 & 14.3 & 0 \\
\hline 11 & 9.1 & 0 \\
\hline 13 & 7.7 & 0 \\
\hline 17 & 5.9 & 0 \\
\hline 19 & 5.3 & 0 \\
\hline 23 & 4.3 & 0 \\
\hline 25 & 4 & 0 \\
\hline 29 & 3.4 & 0 \\
\hline 31 & 3.2 & 0 \\
\hline
\end{tabular}

The main goal of magnetic flux density calculation is to determine whether or not the values of magnetic flux density generated by the overhead distribution line exceed the prescribed values. Thus, in Figure $4 \mathrm{~b}$, the maximum calculated values of magnetic flux density harmonics are shown together with the ICNIRP reference levels for exposure to time varying magnetic fields [18]. Calculations are performed over the lateral profile 
from $-20 \mathrm{~m}$ to $+20 \mathrm{~m}$ from distribution line axis, at a height of $1 \mathrm{~m}$ above ground surface. Calculations are performed for the assumed minimum conductor heights, where the highest magnetic flux density values are expected [30].

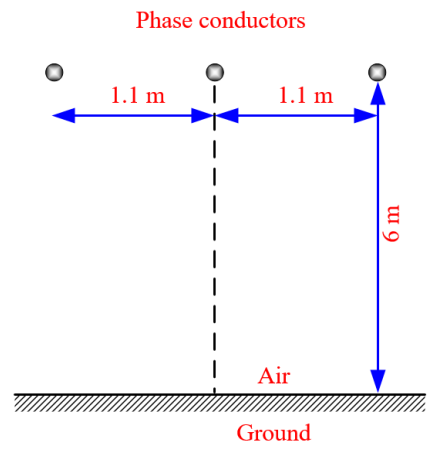

(a)

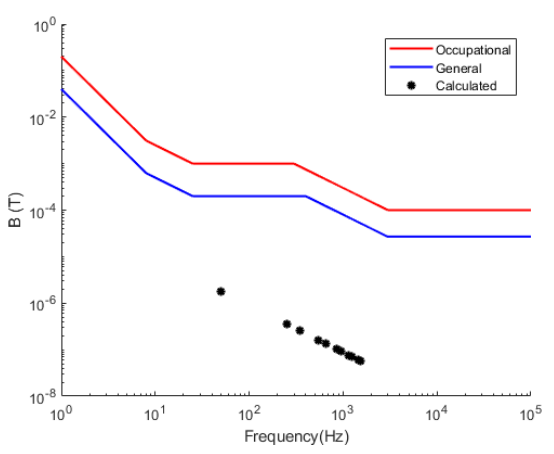

(b)

Figure 4. Considered $10 \mathrm{kV}$ overhead distribution line case. (a) $10 \mathrm{kV}$ overhead distribution line configuration. (b) Comparison with ICNIRP reference values.

From Figure $4 \mathrm{~b}$ it can be noted that all magnetic flux density harmonics, in the considered case study, satisfy prescribed limit values for both general and occupational exposure. In addition, ICNIRP proposes criteria for simultaneous exposure to multiple frequency fields [18]. These criteria are originally defined for magnetic field strength, but in this paper they are adjusted for the magnetic flux density. Taking into account the relationship between the magnetic field strength and the magnetic flux density, the criteria can be defined by the following equation:

$$
\sum_{j=1 \mathrm{~Hz}}^{10 \mathrm{MHz}} \frac{B_{j}}{B_{R, j}} \leq 1,
$$

where $B_{j}$ is magnetic flux density at frequency $j$, and $B_{R, j}$ is magnetic flux density reference level at frequency $j$ for professional or general public exposure.

Taking into account magnetic flux densities of all present harmonics, the sum from Equation (15) corresponds to a value of $4.8 \times 10^{-3}$, which is significantly less than 1 . The general public exposure reference values are used for calculation. Considering that occupational exposure reference values are larger, it can be concluded that for this test case exposure limits are satisfied in all conditions.

Taking into account that a typical overhead distribution line is analysed under the assumption that phase current intensity is equal to the conductor ampacity, information that even in the most difficult load conditions will not violate the prescribed reference values is very significant. This is especially relevant for densely populated areas, where distribution lines are widespread.

Figure 5a presents the magnetic flux density distributions associated with the fundamental harmonic, the total magnetic flux density where contributions of the entire analyzed harmonic spectrum are taken into account, and the magnetic flux density where only a limited harmonic spectrum is considered (only those harmonics with values higher than $5 \%$ of fundamental harmonic are considered). Figure $5 \mathrm{~b}$ shows the distribution of magnetic flux density higher order harmonics over the considered lateral profile. 


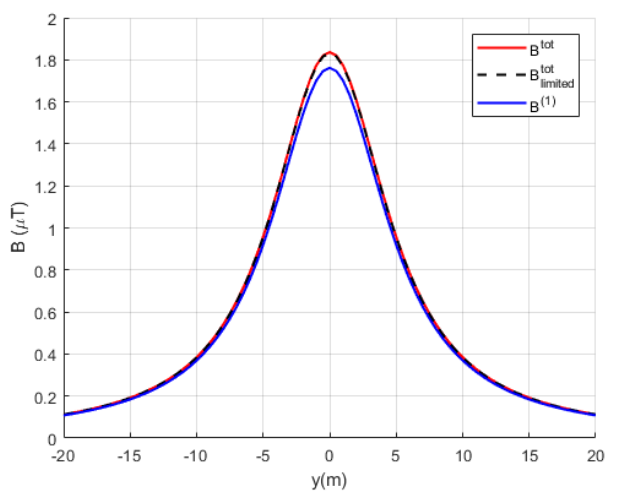

(a)

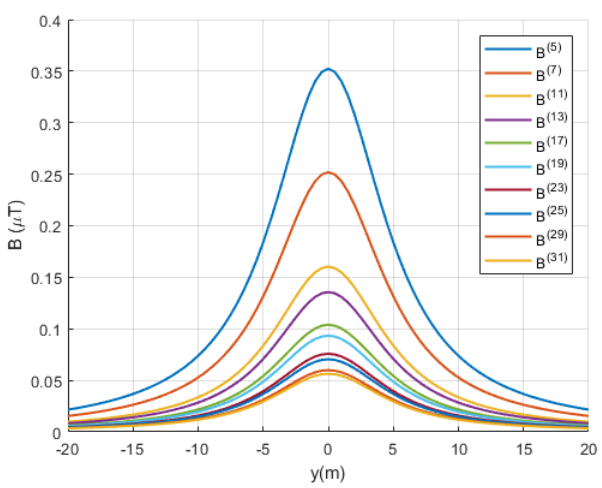

(b)

Figure 5. Magnetic flux density distribution for the analysed $10 \mathrm{kV}$ overhead distribution line. (a) Fundamental harmonic and total magnetic flux density. (b) Higher harmonics magnetic flux density.

It can be noted from Figure 5 that all considered magnetic flux density harmonics as well as the total magnetic flux density have a maximum value at the distribution line axis. The maximum calculated values of magnetic flux density in Figure $5 \mathrm{a}$ are $1.84 \mu \mathrm{T}$ for total magnetic flux density with entire harmonic spectrum, $1.83 \mu \mathrm{T}$ for limited harmonic spectrum and $1.76 \mu \mathrm{T}$ for fundamental harmonic magnetic flux density. The relative error between the total magnetic flux densities, when the entire harmonic spectrum and limited harmonic spectrum were taken into account, is $-0.54 \%$. On the other hand, the highest relative error between the magnetic flux densities corresponding to a case when the entire harmonic spectrum is considered, and a case when only the fundamental harmonic is taken into account, is equal to $-4.35 \%$. The observed difference between these three values is due to the presence of higher current harmonics which cause higher magnetic flux density harmonics.

Fundamental harmonic magnetic flux density, total magnetic flux density and magnetic flux density limited to harmonics higher than $5 \%$ over one period are shown in Figure 6. Magnetic flux density waveforms correspond to the point directly under the central phase conductor, where magnetic flux density reaches the maximum value for all considered harmonics. The total magnetic flux density waveforms when higher harmonics presence was taken into account are obtained by superimposing the waveforms of all considered magnetic flux density harmonics.

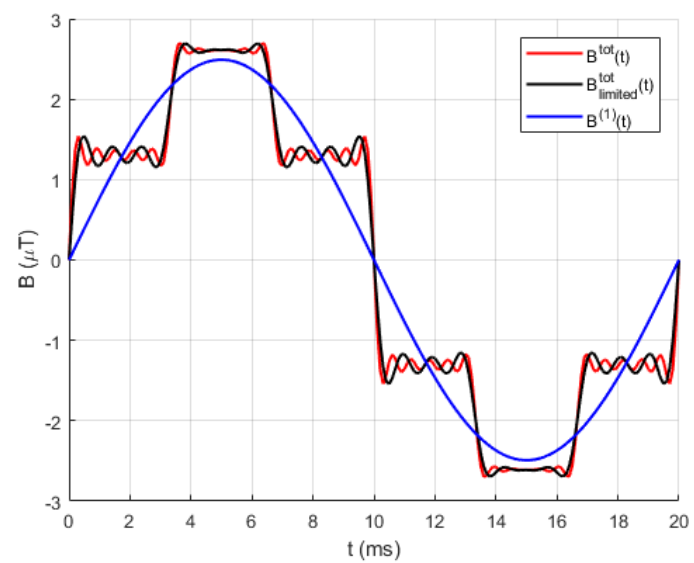

Figure 6. Magnetic flux density waveform for analysed $10 \mathrm{kV}$ overhead distribution line.

As it can be noted from Figure 6 fundamental harmonic magnetic flux density have the sine waveform, while other two magnetic flux densities have distorted waveforms due to the presence of higher current harmonics. Also, it can be noted that magnetic flux densities for cases of entire and limited harmonic spectrum have similar waveforms with minor deviations. 


\subsection{Overhead Distribution Line of $35 \mathrm{kV}$ Rated Voltage}

Phase conductor arrangement of the second analysed overhead distribution line is presented in Figure 7a. The calculations are performed for the rated current of phase conductors and in the presence of higher current harmonics. For the analysed $35 \mathrm{kV}$ rated voltage distribution line, the current intensity of fundamental harmonic of $300 \mathrm{~A}$ is assumed. The harmonic spectrums used in this case are the same as in the previous case. In Figure $7 \mathrm{~b}$, the maximum calculated values of magnetic flux density harmonics are shown together with the ICNIRP reference levels for exposure to time varying magnetic fields [18]. Calculations are performed over the lateral profile from $-20 \mathrm{~m}$ to $+20 \mathrm{~m}$ from distribution line axis, with increments of $1 \mathrm{~m}$. Calculations are performed at a height of $1 \mathrm{~m}$ above ground surface.

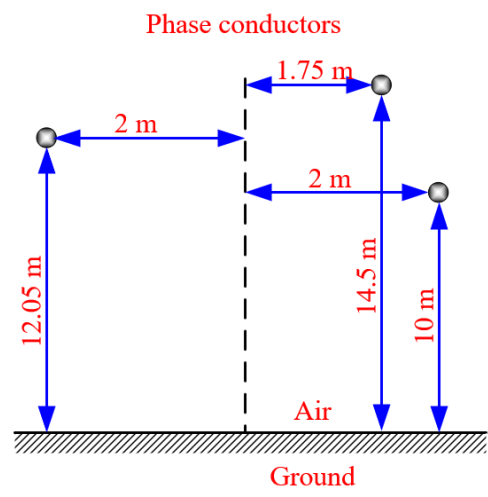

(a)

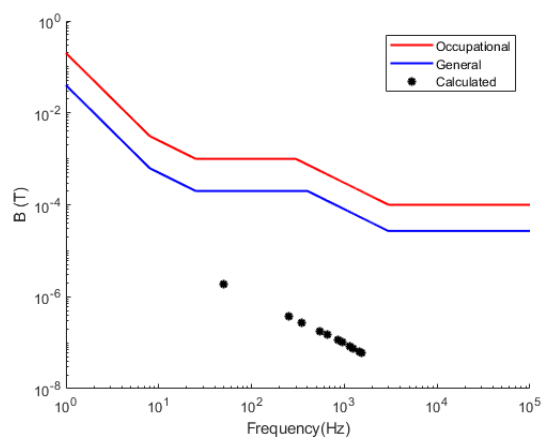

(b)

Figure 7. Considered $35 \mathrm{kV}$ overhead distribution line case. (a) $35 \mathrm{kV}$ overhead distribution line configuration. (b) Comparison with ICNIRP reference values.

In this case, as in the previous one, all magnetic flux density harmonics are lower than both prescribed limit values for the general and occupational exposure. Applying the ICNIRP criteria for simultaneous exposure to multiple frequency magnetic fields, the obtained sum for stricter limits, defined in Equation (15) amounts to $5.2 \times 10^{-3}$, which means that also in this considered case, exposure restrictions are satisfied.

The comparison of magnetic flux density distribution for fundamental harmonics as well as the total magnetic flux density, where contributions of the entire analysed harmonic spectrum and limited harmonic spectrum are considered, are shown in Figure 8a. The magnetic flux density of higher order harmonics over the considered lateral profile is shown in Figure 8b.

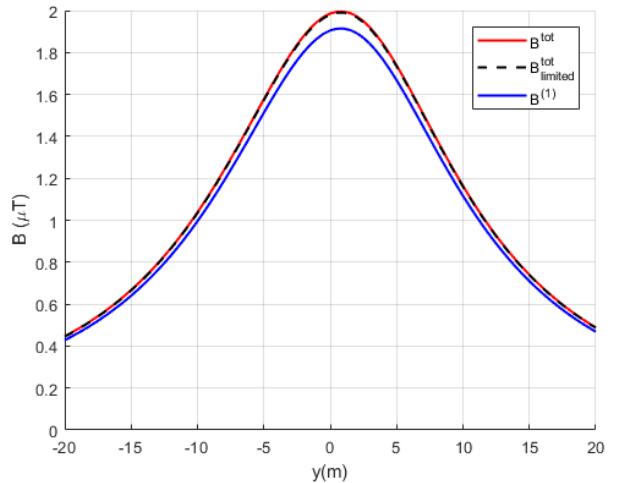

(a)

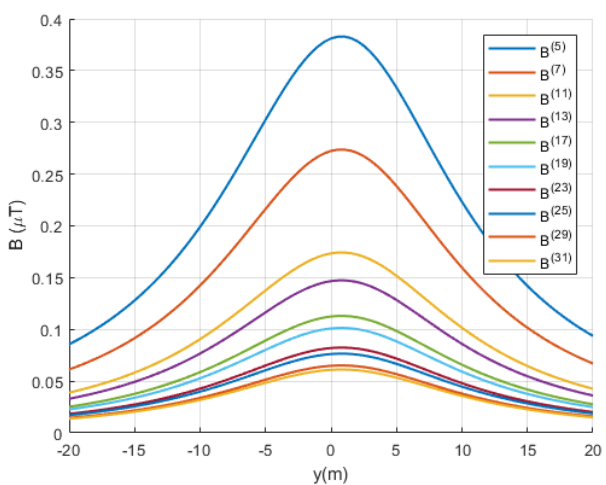

(b)

Figure 8. Magnetic flux density distribution for analysed $35 \mathrm{kV}$ overhead distribution line. (a) Fundamental harmonic and total magnetic flux density. (b) Higher harmonics magnetic flux density.

The maximum calculated value of the fundamental harmonic magnetic flux density shown in Figure 8a is $1.91 \mu \mathrm{T}$. On the other hand, the maximum values of the total magnetic 
field density for case of entire and limited harmonic spectrum are $2.00 \mu \mathrm{T}$ and $1.99 \mu \mathrm{T}$, respectively. The highest relative error between total magnetic flux densities when entire harmonic spectrum and limited harmonic spectrum were taken into account is $-0.5 \%$. The highest relative error between the magnetic flux densities corresponding to a case when entire harmonic spectrum is considered, and a case when only fundamental harmonic is taken into account, is equal to $-4.5 \%$. It is noticeable that in this case, the higher current harmonics have a significant impact on the calculated magnetic flux density values, as in the previous case.

Fundamental harmonic magnetic flux density waveform, magnetic flux density waveform obtained by taking into account entire harmonic spectrum and magnetic flux density taking into account limited harmonic spectrum for the analysed $35 \mathrm{kV}$ overhead distribution line are shown in Figure 9. The waveform correspond to a particular point in the considered lateral profile where maximum magnetic flux density values are attained.

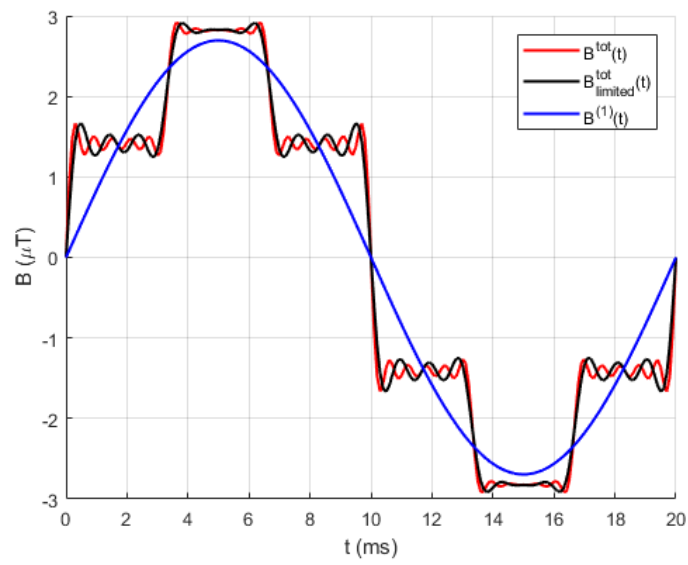

Figure 9. Magnetic flux density waveform for analysed $35 \mathrm{kV}$ overhead distribution line.

Figure 9 demonstrates the distortion of magnetic flux density waveform due to the impact of the current harmonics. The total magnetic flux density waveform is dependent on the current harmonic spectrum.

Magnetic flux density THD, over the entire considered lateral profile, is $29.42 \%$ in both considered case studies and, as expected, it is equal to current intensity THD. At all analyzed points, the ratio of the magnetic flux density of the higher harmonic to the fundamental harmonic magnetic flux density is also constant and equal to the ratio of the current of the corresponding higher harmonic to the fundamental harmonic current.

The obtained results, in all analysed cases, undoubtedly show the significance of magnetic flux density harmonics in the magnetic flux density exposure analysis. The magnetic flux density harmonics are especially important when analyzing overhead distribution lines, due to the their harmonic pollution as well as population proximity.

\section{Conclusions}

This paper consider a method for the calculation of magnetic flux density harmonics in the vicinity of overhead lines. The considered method is based on the BS law. The validation of the calculation method is done by comparison of the results obtained by the considered calculation method with the measurement results. In addition, the considered method is applied for magnetic flux density harmonics calculation of two typical overhead distribution lines. The obtained results show the difference between the fundamental harmonic magnetic flux density and the resultant value obtained when the higher current harmonics are taken into consideration. The observed differences emphasize the significance of magnetic flux density harmonics analyses, especially in situations where the obtained magnetic flux density values are close to the prescribed values.

Results presented within the paper showed that, when calculating the magnetic flux density caused by harmonics distorted current, the magnetic flux density waveform 
will also be distorted. In addition, it was shown that if current harmonics with a small percentage share are neglected, this will have a slight effect on a calculated total value of the magnetic flux density. Specifically, it was shown that when the share of current harmonics is lower than $5 \%$, they can be neglected without introducing any significant errors in the results of the total magnetic flux density calculation. Such an approximation further reduces the calculation time, since the total current harmonic spectrum does not need to be considered.

Author Contributions: A.M., E.T. and A.A. have implemented the magnetic flux density calculation method. Writing and editing, A.M., E.T., A.A., M.M.D. and N.D. All authors have read and agreed to the published version of the manuscript.

Funding: This research and publication was funded by Ministry for Science, Higher Education and Youth of Sarajevo Canton.

Institutional Review Board Statement: Not applicable.

Informed Consent Statement: Not applicable.

Data Availability Statement: Not applicable.

Conflicts of Interest: The authors declare no conflict of interest.

\section{References}

1. Barutcu, I.C.; Karatepe, E.; Boztepe, M. Impact of harmonic limits on PV penetration levels in unbalanced distribution networks considering load and irradiance uncertainty. Int. J. Electr. Power Energy Syst. 2020, 118, 105780. [CrossRef]

2. Wang, R.; Tian, J.; Wu, F.; Zhang, Z.; Liu, H. PSO/GA Combined with Charge Simulation Method for the Electric Field Under Transmission Lines in 3D Calculation Model. Electronics 2019, 8, 1140. [CrossRef]

3. Michalec, Ł.; Jasiński, M.; Sikorski, T.; Leonowicz, Z.; Jasiński, Ł.; Suresh, V. Impact of Harmonic Currents of Nonlinear Loads on Power Quality of a Low Voltage Network-Review and Case Study. Energies 2021, 14, 3665. [CrossRef]

4. Maan, J.S.; Singh, S.; Singh, A. Impact of Harmonics on Power Transformer Losses and Capacity Using Open DSS. Int. J. Emerg. Electr. Power Syst. 2019, 20, 20180349. [CrossRef]

5. Lumbreras, D.; Gálvez, E.; Collado, A.; Zaragoza, J. Trends in Power Quality, Harmonic Mitigation and Standards for Light and Heavy Industries: A Review. Energies 2020, 13, 5792. [CrossRef]

6. Sinvula, R.; Abo-Al-Ez, K.M.; Kahn, M.T. A Proposed Harmonic Monitoring System for Large Power Users Considering Harmonic Limits. Energies 2020, 13, 4507. [CrossRef]

7. IEEE Std 519-2014 (Revision of IEEE Std 519-1992); IEEE Recommended Practice and Requirements for Harmonic Control in Electric Power Systems. IEEE: Piscataway, NJ, USA, 2014; pp. 1-29. [CrossRef]

8. EN 50160:2010/A3:2019 (AMENDMENT); Voltage Characteristics of Electricity Supplied by Public Electricity Networks. British Standards Institute: London, UK, 2019.

9. IEC 61000-3:2021; SER—Series Electromagnetic Compatibility (EMC)—Part 3: Limit-ALL PARTS. International Electrotechnical Commission: Geneva, Switzerland, 2021.

10. Aziz, M.H.A.; Azizan, M.M.; Sauli, Z.; Yahya, M.W. A review on harmonic mitigation method for non-linear load in electrical power system. AIP Conf. Proc. 2021, 2339, 020022. [CrossRef]

11. Kazem, H.A. Harmonic Mitigation Techniques Applied to Power Distribution Networks. Adv. Power Electron. 2013, 2013, 591680. [CrossRef]

12. Chakravorty, D.; Meyer, J.; Schegner, P.; Yanchenko, S.; Schocke, M. Impact of Modern Electronic Equipment on the Assessment of Network Harmonic Impedance. IEEE Trans. Smart Grid 2017, 8, 382-390. [CrossRef]

13. Gallastegi, M.; Zabala, A.; Santa Marina, L.; Aurrekoetxea, J.; Ayerdi, M.; Ibarluzea, J.; Kromhout, H.; González, J.; Huss, A. Exposure to extremely low and intermediate-frequency magnetic and electric fields among children from the INMA-Gipuzkoa cohort. Environ. Res. 2017, 157, 190-197. [CrossRef]

14. Amoon, A.; Crespi, C.; Ahlbom, A.; Bhatnagar, M.; Bray, I.; Bunch, K.; Clavel, J.; Feychting, M.; Hémon, D.; Johansen, C.; et al. Proximity to overhead power lines and childhood leukaemia: An international pooled analysis. Br. J. Cancer 2018, 119. [CrossRef] [PubMed]

15. Crespi, C.M.; Swanson, J.; Vergara, X.P.; Kheifets, L. Childhood leukemia risk in the California Power Line Study: Magnetic fields versus distance from power lines. Environ. Res. 2019, 171, 530-535. [CrossRef] [PubMed]

16. Pedersen, C.; Johansen, C.; Schüz, J.; Olsen, J.; Raaschou-Nielsen, O. Residential exposure to extremely low-frequency magnetic fields and risk of childhood leukaemia, CNS tumour and lymphoma in Denmark. Br. J. Cancer 2015, 113, 1370-1374. [CrossRef] [PubMed]

17. Karimi, A.; Ghadiri Moghaddam, F.; Valipour, M. Insights in the biology of extremely low-frequency magnetic fields exposure on human health. Mol. Biol. Rep. 2020, 47, 5621-5633. [CrossRef] 
18. Lin, J.; Saunders, R.; Schulmeister, K.; Söderberg, P.; Stuck, B.; Swerdlow, A.; Taki, M.; Veyret, B.; Ziegelberger, G.; Repacholi, M.; et al. ICNIRP Guidelines for limiting exposure to time-varying electric and magnetic fields (1 Hz to $100 \mathrm{kHz})$. Health Phys. 2010, 99, 818-836. [CrossRef]

19. Wu, T.; Xiao, B.; Liu, K.; Liu, T.; Peng, Y.; Su, Z.; Tang, P.; Lei, X. Study on overhead transmission line magnetic field harmonics of VSC-HVDC. In Proceedings of the IEEE International Conference on High Voltage Engineering and Application (ICHVE), Chengdu, China, 19-22 September 2016; pp. 1-4. [CrossRef]

20. Brandao Faria, J.; Almeida, M. Computation of transmission line magnetic field harmonics. Int. Trans. Electr. Energy Syst. 2007, 17, 512-525. [CrossRef]

21. Mujezinovic, A.; Dautbasic, N.; Dedovic, M.M. More Accurate 2D Algorithm for Magnetic Field Calculation Under Overhead Transmission Lines. In Advanced Technologies, Systems, and Applications IV, Proceedings of the International Symposium on Innovative and Interdisciplinary Applications of Advanced Technologies (IAT 2019), Sarajevo, Bosnia and Herzegovina, 20-23 June 2019; Springer: Cham, Switzerland, 2019.

22. Alihodzic, A.; Mujezinovic, A.; Turajlic, E. Electric and Magnetic Field Estimation Under Overhead Transmission Lines Using Artificial Neural Networks. IEEE Access 2021, 9, 105876-105891. [CrossRef]

23. Salari, J.; Mpalantinos, A.; Silva, J. Comparative Analysis of 2-D and 3-D Methods for Computing Electric and Magnetic Fields Generated by Overhead Transmission Lines. IEEE Trans. Power Deliv. 2009, 24, 338-344. [CrossRef]

24. Boteler, D.; Pirjola, R. The complex-image method for calculating the magnetic and electric fields at the surface of the Earth by the auroral electrojet. Geophys. J. Int. 1998, 132, 31-40. [CrossRef]

25. Keikko, T.; Seesvuori, R.; Valkealahti, S. Exposure to magnetic field harmonics in the vicinity of indoor distribution substations. Health Phys. 2006, 91, 574-581. [CrossRef]

26. Hejase, H.; Shaltout, A. Impact of Third Harmonic Currents on Magnetic Field Measurements from Distribution Lines. Electr. Power Compon. Syst. 2004, 32, 353-366. [CrossRef]

27. Rohatgi, A. Webplotdigitizer: Version 4.5, 2021. Available online: https://automeris.io/WebPlotDigitizer/citation.html (accessed on 29 December 2021).

28. Milovanović, M.; Radosavljević, J.; Perović, B. A backward/forward sweep power flow method for harmonic polluted radial distribution systems with distributed generation units. Int. Trans. Electr. Energy Syst. 2020, 30, e12310. [CrossRef]

29. Ulinuha, A.; Masoum, M.; Islam, S. Harmonic power flow calculations for a large power system with multiple nonlinear loads using decoupled approach. In Proceedings of the Australasian Universities Power Engineering Conference, Perth, Australia, 9-12 December 2007; pp. 1-6. [CrossRef]

30. IEEE Std 644-2019 (Revision of IEEE Std 644-2008); IEEE Standard Procedures for Measurement of Power Frequency Electric and Magnetic Fields from AC Power Lines. IEEE: Piscataway, NJ, USA, 2020; pp. 1-40. 